\title{
FORBIDDEN LINE EXCITATION DATA FOR CERTAIN CORONAL LINES
}

\author{
S. J. CZYZAK \\ Astronomy Dept., The Ohio State University, Columbus, Ohio, U.S.A. \\ L. H. A LLER \\ Astronomy Dept., University of California, Los Angeles, Calif., U.S.A. \\ and \\ R. N. EUWEMA \\ Aerospce Research Laboratories, Wright Patterson Air Force Base, Ohio, U.S.A.
}

\begin{tabular}{|c|c|c|c|c|c|c|c|c|c|}
\hline Ion & $\begin{array}{l}\text { Con- } \\
\text { fig. }\end{array}$ & $\begin{array}{l}\lambda \\
(\AA)\end{array}$ & $\begin{array}{l}A \\
\left(\mathrm{~s}^{-1}\right)\end{array}$ & $\Omega$ & Ion & $\begin{array}{l}\text { Con- } \\
\text { fig. }\end{array}$ & $\begin{array}{l}\lambda \\
(\AA)\end{array}$ & $\begin{array}{l}A \\
\left(\mathrm{~s}^{-1}\right)\end{array}$ & $\Omega$ \\
\hline$S_{\text {II }}$ & $2 p$ & 7536 & 20.817 & 0.1178 & $\mathrm{Ni} x \mathrm{XI}$ & $3 p$ & 3600.9 & 190.80 & 0.170 \\
\hline Ca XIII & $2 p^{4}$ & 4086.5 & 315.7 & 0.1140 & $\mathrm{Ni} x \mathrm{v}$ & $3 p^{2}$ & 8024.2 & 22.121 & 0.249 \\
\hline K XI & $2 p^{5}$ & 4256 & 231.13 & 0.1093 & & & 6701.9 & 55.820 & 0.038 \\
\hline Mn XIII & $3 p$ & 6535.4 & 31.922 & 0.2270 & Cr IX & $3 p^{4}$ & 4451 & 4.308 & 0.112 \\
\hline Fe XIV & $3 p$ & 5302.9 & 60.056 & 0.1950 & Fe $x$ & $3 p^{5}$ & 6374.5 & 69.149 & 0.286 \\
\hline Co Xv & $3 p$ & 4351.4 & 108.16 & 0.1851 & $\mathrm{Ni}$ XII & $3 p^{5}$ & 4232.3 & 235.26 & 0.219 \\
\hline
\end{tabular}

We have calculated and tabulated occupation numbers of the upper excited levels and corresponding emissivities as a function of electron density and temperature following a procedure similar to that of Zirker (Solar Phys. 11, 68, 1970). These numbers almost certainly represent lower limits to the quantities involved since at coronal temperatures one must consider collisional excitation to high permitted levels from which cascade can occur, dielectronic recombination of the pertinent ions, and subsequent decay to the level involved, and also collisional excitation and ionization which serve to remove ions from the level considered. A rigorous calculation would require accurate knowledge of all relevant transition probabilities, collision cross sections, and dielectronic recombination parameters. The effects are more severe at the higher densities and can be estimated only when we know the necessary parameters. The present numbers may prove useful for lower densities and temperatures and higher stages of ionization. 